Revue des patrimoines

33 | 2017

Patrimoine culturel immatériel et institutions patrimoniales

\title{
Sauvegarder le patrimoine, sauvegarder l'individu. Un regard sur la politique patrimoniale de l'immatériel au Brésil
}

Safeguarding the heritage, safeguarding individuals. Intangible heritage policies in Brazil

\section{Elaine Brito et Nolwenn Pianezza}

\section{(2) OpenEdition}

Journals

Édition électronique

URL : http://journals.openedition.org/insitu/15639

DOI : $10.4000 /$ insitu. 15639

ISSN : $1630-7305$

Éditeur

Ministère de la culture

\section{Référence électronique}

Elaine Brito et Nolwenn Pianezza, « Sauvegarder le patrimoine, sauvegarder l'individu. Un regard sur la politique patrimoniale de l'immatériel au Brésil », In Situ [En ligne], 33 | 2017, mis en ligne le 09 novembre 2017, consulté le 01 mai 2019. URL : http://journals.openedition.org/insitu/15639 ; DOI 10.4000/insitu. 15639

Ce document a été généré automatiquement le 1 mai 2019.

\section{c) (†)}

In Situ Revues des patrimoines est mis à disposition selon les termes de la licence Creative Commons Attribution - Pas d'Utilisation Commerciale - Pas de Modification 4.0 International. 


\title{
Sauvegarder le patrimoine, sauvegarder l'individu. Un regard sur la politique patrimoniale de l'immatériel au Brésil
}

\author{
Safeguarding the heritage, safeguarding individuals. Intangible heritage policies
} in Brazil

Elaine Brito et Nolwenn Pianezza

\section{Introduction ${ }^{1}$}

Le concept contemporain de patrimoine immatériel semble aujourd'hui aller de pair avec l'idée de sa sauvegarde, et l'appareil conséquent de dispositifs nationaux et internationaux destiné à la mettre en œuvre. Au Brésil en particulier, l'action patrimoniale liée à l'immatériel est fondamentalement ancrée dans l'idée de sauvegarde, comprise comme un moment-clé de la patrimonialisation. C'est en effet au cours de la seconde moitié $\mathrm{du} \mathrm{xx}^{\mathrm{e}}$ siècle que le concept de sauvegarde a trouvé des résonances profondes, et sensiblement transformé l'approche patrimoniale du pays. Rapidement approprié, tant par le politique que par la société civile, le concept de sauvegarde semble venir y répondre à un besoin de refonder le rapport du patrimoine à l'acteur social considéré détenteur et praticien de ce patrimoine - et de resituer la place de ce dernier au cœur des processus à caractère patrimonialisant. Nous retracerons ici le cheminement du concept de sauvegarde à partir du contexte brésilien et en approfondirons une approche particulière tenant à la sauvegarde de l'acteur social lui-même, telle que nous la repérons sur le terrain à travers le récit de plusieurs interlocuteurs ${ }^{2}$ rencontrés en entretien. Ceci nous permettra de mieux saisir la teneur singulière de la politique contemporaine du patrimoine immatériel au Brésil et d'en apprécier la nature spécifiquement orientée vers le bien-être socio-économique des praticiens et détenteurs de ce patrimoine. Nous envisagerons alors la place particulière de l'acteur social dans ce 
paysage contemporain et avant cela, la manière dont il a conquis cette place. Nous exposerons ici le processus de construction de l'acteur social : à travers un panorama historique et législatif de la fin du $\mathrm{xx}^{\mathrm{e}}$ jusqu'au début du $\mathrm{xxI}^{\mathrm{e}}$ siècle ${ }^{3}$, nous mettrons au jour la naissance d'une nouvelle citoyenneté politique et patrimoniale. Il s'agira ensuite de comprendre la progressive mise en capacité du citoyen qui se dote de compétences nouvelles pour agir sur son propre patrimoine. À travers ces réflexions, nous réfléchirons au rôle singulier que ce dernier a joué dans la mise en place du cadre institutionnel patrimonial et la manière dont il a spécifiquement influé sur sa nature, pour aboutir à l'idée englobante de sauvegarde, organisatrice de la politique patrimoniale de l'immatériel au Brésil, telle que nous la concevons aujourd'hui.

\section{Naissance d'une citoyenneté politique et patrimoniale}

2 Afin de comprendre la particularité des politiques patrimoniales brésiliennes et le rôle moteur de l'acteur social dans la formulation de l'idée de sauvegarde patrimoniale, il nous faut tout d'abord en dresser un panorama législatif. En premier lieu, il convient ici de rappeler «la conjoncture favorable du pays à la refonte de ces politiques, à partir du processus de démocratisation mis en route à la fin des années $1980^{4}$ ", mû par la force d'un mouvement militant naissant. C'est ici que nous comprendrons l'influence décisive de l'acteur social sur la nature même des politiques sociales, culturelles et patrimoniales au Brésil.

3 Lorsque, dès 1983, le mouvement civil en faveur de la démocratisation prend de l'ampleur, il ne revendique pas moins que la fin du régime dictatorial (1964-1985), signalant l'éveil d'une citoyenneté politique naissante, agissante et influente, une force citoyenne avec laquelle il faut désormais compter au moment de façonner les politiques publiques brésiliennes.

Le mouvement se mobilise premièrement pour exiger le retour au suffrage universel par le vote direct aux élections présidentielles. Cette première campagne citoyenne, emmenée par le célèbre slogan «Diretas já! »", suscite alors un extraordinaire engouement, au point d'être qualifiée de plus grande campagne civique de l'histoire républicaine du Brésil ${ }^{6}$ et signale bien l'entrée en scène de l'acteur social, désormais positionné comme acteur incontournable et partie prenante du jeu politique (fig. 1). 
Figure 1

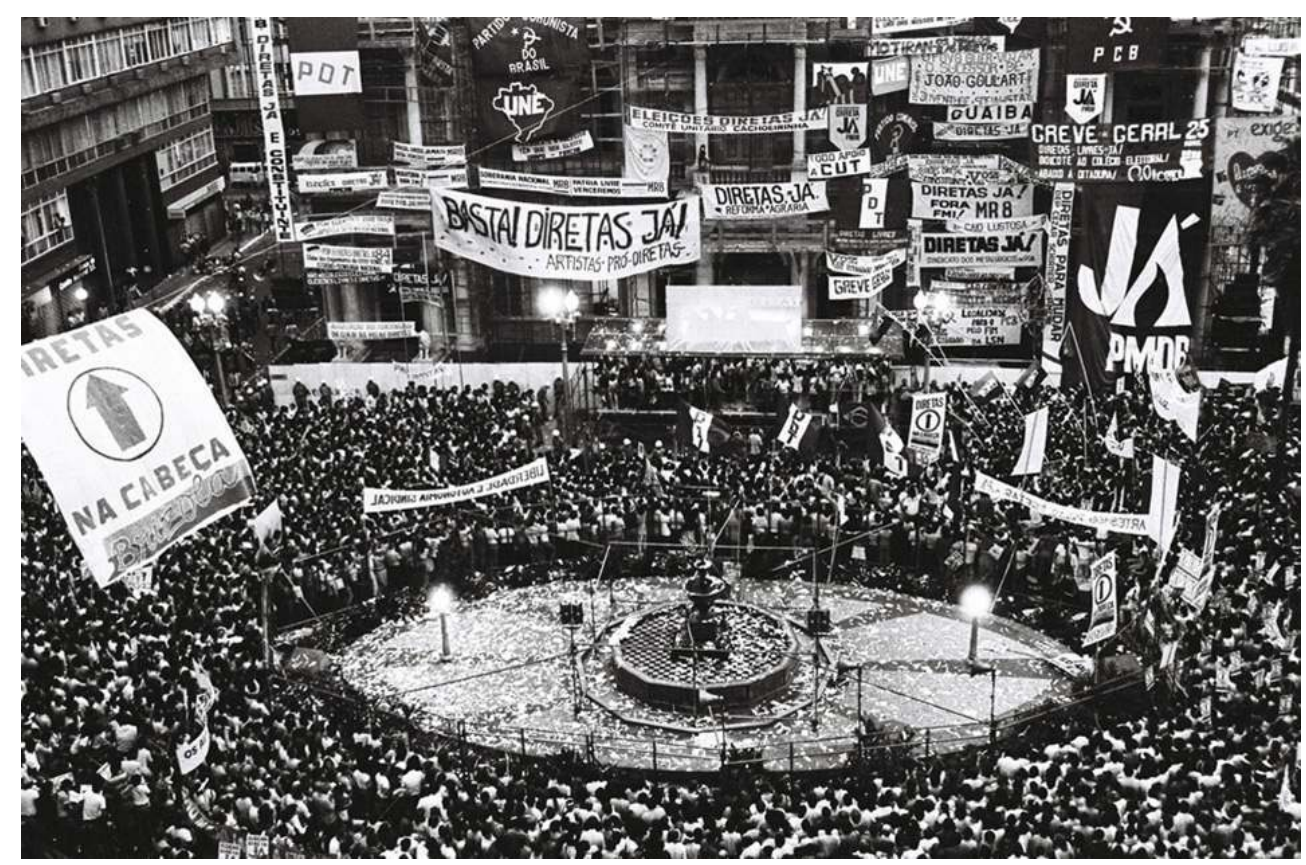

Campagne «Diretas já! », le 13 mars 2014 à Porto Alegre, dans la Région du Rio Grande do Sul, Brésil. Phot. Alfonso Abraham. (c) Senado Federal.

5 Ainsi, même si le Congrès national rejette le vote direct en avril 1984, la campagne aura constitué un épisode-phare de la transition démocratique et un tremplin vers de nouvelles initiatives en sa faveur. Hautement symbolique de par l'union sacrée qu'elle aura permise entre les partis d'opposition d'une part et les citoyens de divers horizons socioculturels d'autre part, la campagne «Diretas já! » aura ainsi révélé à tous les acteurs en présence la capacité de la société civile à mobiliser rapidement et en nombre des forces considérables. Unie derrière la revendication commune de ses droits civiques, la société brésilienne faisait ici l'expérience d'un sentiment rarement éprouvé de communion nationale entre institutions et mouvements populaires ${ }^{7}$. Pour la première fois, elle se voyait rassemblée en une force vive et percevait le poids politique qu'elle pouvait potentiellement représenter face à l'État. Ainsi, loin de décourager les mouvements populaires, cette victoire en demi-teinte prend l'allure d'un nouveau départ qui enhardit l'acteur social, désormais conscient de son influence sur la chose publique et de l'opportunité qui s'offre à lui d'y participer. Par-delà le symbolique, quelques avancées notables sont toutefois acquises suite à la campagne; signe d'un renouvellement de la classe politique et de l'ouverture progressive à l'idée de la participation citoyenne en particulier : pour la première fois depuis 1960, les candidats à la présidentielle sont des " politiciens civils " ${ }^{8}$, et non issus du corps militaire.

6 Éclairant, l'exemple du mouvement «Diretas já!», incarne ainsi tout particulièrement le processus plus vaste de lutte sociale, selon lequel la société civile vise à élargir la démocratie brésilienne, et revendique à ce titre de participer à l'élaboration des politiques nationales. Point culminant de ce mouvement, la Constitution fédérale de 1988 vient couronner ce processus en entérinant la participation de la société civile dans la vie de l'État et reconnaissant sa pertinence'. L'acteur social occupe désormais une place de choix dans la définition des orientations prévues par la Constitution. À tel point que tout 
citoyen est reconnu acteur légitime de la vie publique, habilité à dénoncer, par le biais d'une action populaire, tout acte jugé préjudiciable au bien commun, et au patrimoine historique et culturel en particulier, pour citer un exemple qui touche à notre sujet ${ }^{10}$. La «Constitution citoyenne» de 1988, telle qu'elle est communément appelée, constitue ainsi une première étape vers l'adoption de futurs mécanismes tels que l'initiative populaire et le référendum, destinés à insérer formellement l'acteur social dans ce processus décisionnel. Désormais, "le peuple détient l'initiative de la loi », nous dit Ulysses Guimarães, président de l'Assemblée nationale constituante ${ }^{11}$. «Plus que cela, le peuple est aujourd'hui le législateur suprême ${ }^{12}$.» (fig. 2)

Figure 2

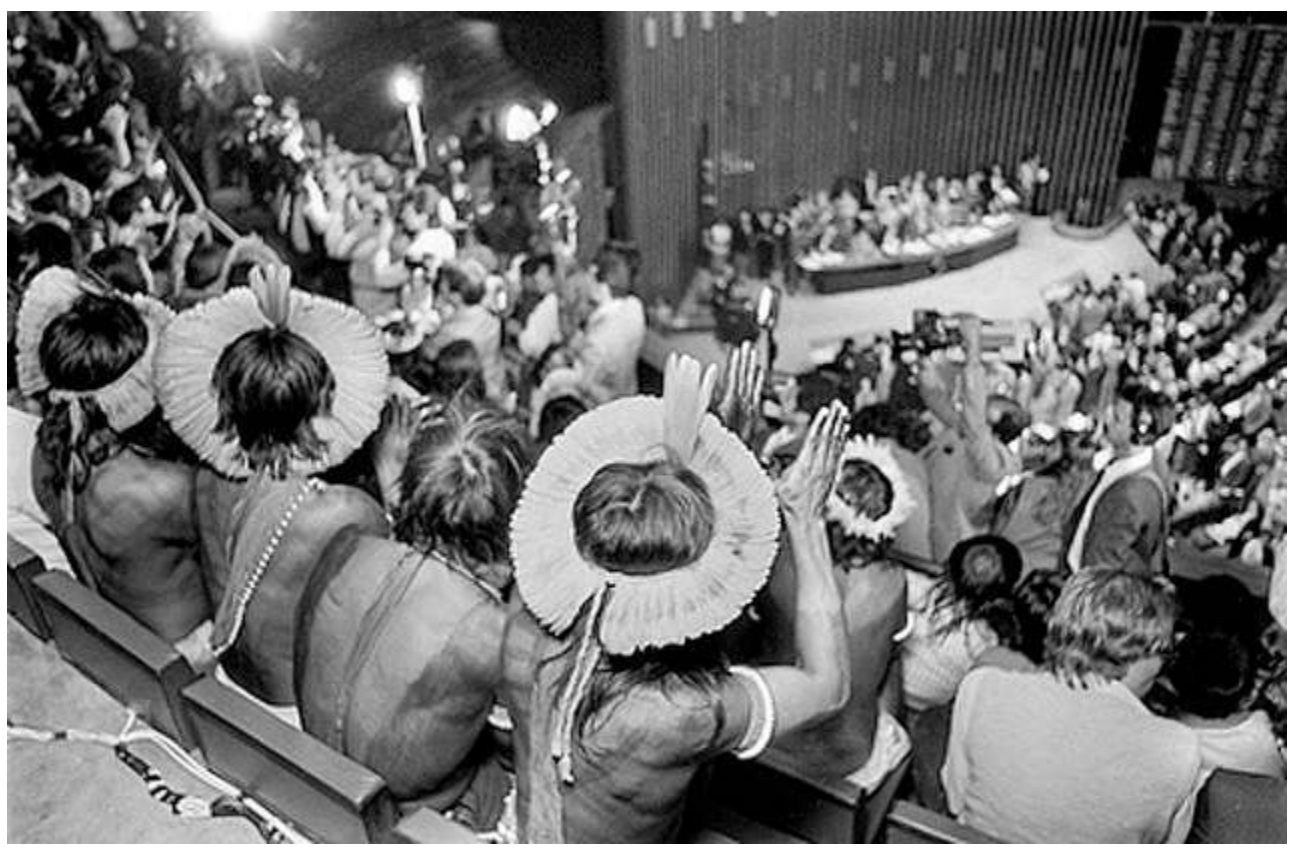

Les différents groupes ethniques soutiennent la mise en place de la nouvelle Constitution fédérale depuis le congrès national, en 1988.

(c) Senado Federal.

7 Sur le plan culturel, il n'en est pas autrement et l'Association brésilienne d'anthropologie (ABA) n'y est pas étrangère. Elle participe en effet directement à l'écriture de plusieurs articles de la Constitution et vient en infléchir le contenu pour accorder une plus large place aux déterminations de l'acteur social au sein du texte. Si leur contribution signale combien la discipline étend maintenant son influence au champ de la politique culturelle ${ }^{13}$, elle nous fait envisager le tournant que représente la Constitution aux niveaux culturel et patrimonial. En effet, l'engagement au Brésil des anthropologues auprès des groupes sociaux liés à leur recherche, et pour lesquels ils font souvent figure de porte-parole, aura certainement contribué à la reconnaissance de ces entités et de leur patrimoine au sein du texte. De fait, c'est sous l'impulsion des anthropologues sollicités comme experts que le texte de la Constitution ${ }^{14}$ en vient à reconnaître officiellement les biens culturels immatériels, leur accorde le statut patrimonial et les relie de manière intrinsèque à la communauté de ses détenteurs, les praticiens dont ils sont issus.

8 Ainsi, la Constitution citoyenne refonde le concept de patrimoine culturel, désormais interprété selon la compréhension anthropologique de la culture et l'idée de la référence 
culturelle $^{15}$ - nous reviendrons plus tard sur ce second point. Le concept de culture est alors envisagé de manière processuelle afin de "promouvoir et diffuser une notion de culture qui intègre les idées de dynamique et de créativité ${ }^{16}$. C'est l'idée que l'individu, l'acteur social, est au centre du patrimoine dont il est détenteur : c'est lui qui le pratique, le fait évoluer, le fait vivre en somme. On admet alors la nécessité que ce patrimoine se transforme au gré de ses détenteurs, la relation à ces derniers devenant primordiale. Le critère patrimonial de la continuité temporelle vaut toujours, mais tient désormais au lien qui perdure de l'individu à son patrimoine - une continuité de pratique - et non au maintien d'une forme, préservée dans son intégrité à travers les âges. Ainsi, le statut patrimonial dépend de la valeur du bien aux yeux de celui qui le pratique et non plus d'un idéal esthétique ou d'une norme scientifique, par exemple. Logiquement, on reconnaît dès lors que «la sauvegarde du patrimoine culturel immatériel doit être centrée sur les conditions de sa production $»^{17}$, et donc garantir aux détenteurs un environnement propice à sa pratique. C'est pourquoi « la sauvegarde du patrimoine immatériel est [...] tournée vers le renforcement des "racines", avec le recours à des mesures d'appui à la production, de valorisation et de diffusion, ainsi qu'aux supports à la mémoire, comme les technologies de documentation et d'information $»^{18}$.

Dès cette époque, on repère aux fondements de la politique brésilienne du patrimoine immatériel une volonté de se distancier de l'idée du tombamento, l'instrument de protection du patrimoine matériel, que l'on rapprocherait de l'idée de classement patrimonial en France ${ }^{19}$. En effet, le tombamento "établit les règles qui empêchent l'altération [de l'objet], sa mutilation ou sa destruction $»^{20}$, de manière à arrêter l'objet dans le temps, le maintenir intact, ou le conserver tel qu'il a été collecté. À l'inverse, l'idée de sauvegarder l'immatériel s'inscrit en faux contre cette perspective et affirme l'évolutivité du patrimoine, continuellement recréé par ses détenteurs: "La culture de groupes spécifiques [...] ne peut pas être envisagée comme un ensemble figé d'éléments inertes qui résisteraient au passage du temps. [...] Certains éléments disparaissent mais d'autres se font jour. Et l'incorporation des nouveaux éléments illustre précisément la vitalité d'une culture [...] » ${ }^{21}$. Dès lors, l'on comprend bien pourquoi le tombamento devient inapplicable pour le patrimoine immatériel: «à l'inverse du tombamento, l'on recommande des mesures dites de sauvegarde $»^{22}$. Le concept de sauvegarde s'impose donc progressivement comme la seule voie possible et acceptable, tandis que le tombamento se pare de connotations négatives, associées à l'idée d'un patrimoine figé.

La politique du patrimoine culturel, ainsi repensé pour incorporer l'idée de l'immatériel, place de nouveau l'acteur social au centre lorsqu'elle se donne pour ambition d'identifier les « références culturelles » des différents peuples constitutifs de la société brésilienne, en vue de les protéger. C'est l'idée que l'on s'intéressera désormais à un patrimoine auparavant ignoréé ${ }^{23}$ et que celui-ci sera désigné par ceux qui le font ${ }^{24}$. Ainsi, proposer d'identifier les références culturelles des Brésiliens, c'est «adopter une perspective plurielle qui tienne compte des significations et des valeurs attribuées aux biens culturels par les différents sujets et/ou groupes sociaux pour lesquels ces biens constituent des marques identitaires $»^{25}$. Ou encore, "mentionner des références culturelles signifie diriger le regard vers des représentations qui configurent une "identité" de la région pour ses habitants $»^{26}$. Ce faisant, l'on reconnaît les «limites de la représentativité du patrimoine culturel $\aleph^{27}$, tel qu'il est défini par le tombamento, et entend renverser cet état de choses. C'est aussi l'idée de « l'évolution du paradigme patrimonial », selon laquelle on admet que le patrimoine est «désormais moins centré sur l'authenticité et 
l'exceptionnalité des œuvres que sur leur représentativité au sein d'une culture et sur les relations construites au fil du temps entre les hommes et leurs créations ${ }^{28}$.

11 Ce faisant, la Constitution pose les jalons de la reconnaissance de l'acteur et de sa participation à la politique patrimoniale brésilienne, d'une citoyenneté patrimoniale, pourrait-on dire. Néanmoins, ce n'est qu'une décennie plus tard qu'émergent les politiques de sauvegarde du patrimoine immatériel, lorsqu'en 1997, l'Instituto do Patrimônio Historico e Artistico Nacional (IPHAN) organise le «séminaire Patrimoine Immatériel : stratégies et formes de protection ${ }^{29}$ ». Réunissant institutions publiques et privées, représentants de l'Unesco et acteurs de la société civile, la réunion liminaire évoquera pour la première fois l'idée de créer « des instruments légaux et administratifs visant à identifier, protéger, promouvoir et subventionner » les biens immatériels ${ }^{30}$.

\section{Mise en capacité de l'acteur social}

12 C'est en effet précisément l'idée de la sauvegarde de l'immatériel qui inspire, à la suite du séminaire sur le patrimoine immatériel de 1997, l'écriture de la «Lettre de Fortaleza » et provoque de manière déterminante le « débat autour des concepts de la sauvegarde des biens immatériels » au Brésil. En particulier, elle amènera donc à s'interroger sur les instruments législatifs à créer afin de préserver ces biens culturels. La Lettre viendra sans aucun doute infléchir la réflexion des différentes parties ${ }^{31}$ et ainsi impulser le développement de la politique patrimoniale brésilienne ${ }^{32}$. En particulier, il est établi que ce travail devra nécessairement être réalisé en partenariat avec la société civile : «ces mesures devront s'adapter aux spécificités des différentes manifestations culturelles, et être formulées avec la participation des pouvoirs publics et de la société $»^{33}$. Le gouvernement brésilien semble ainsi vouloir proposer des actions adaptées aux besoins spécifiques de chaque groupe, et pensées en fonction du groupe.

13 C'est grâce au groupe de travail sur le patrimoine immatériel formé à l'issue du séminaire, qu'est promulgué le 4 août 2000 le décret $n^{\circ} 3.551$ qui institue le Registro ${ }^{34}$, le «Registre des biens culturels de nature immatérielle qui constituent le patrimoine culturel brésilien ». Fondamentalement lié à l'idée de la sauvegarde, le Registre en devient l'instrument. C'est donc par ce moyen que l'on entend mettre en œuvre la sauvegarde, définie dès lors par Gallois comme des «actions qui visent à assurer la viabilité et la durabilité du patrimoine culturel immatériel et peuvent prendre la forme de travaux d'identification, de documentation, de recherche, de préservation, promotion, valorisation, transmission [...] et la revitalisation de ce patrimoine $»^{35}$. Parallèlement à la création du Registro est institué en 2000 le Programme national du patrimoine immatériel ${ }^{36}$, et par là-même une politique publique destinée à favoriser ces travaux ${ }^{37}$. L'une des lignes d'action prévues par le programme consiste notamment à renforcer le tissu de l'organisation communautaire de manière à encourager l'implication des " producteurs ou détenteurs de biens culturels $»$ dans la gestion de leur patrimoine ${ }^{38}$.

Dans la lignée de ce schéma partenarial et de l'implication croissante de l'acteur social au cœur du processus législatif, donc, le ministère de la Culture (MinC) approuve en 2010 le Programme national de la culture (PNC), un texte qui vise notamment à promouvoir la participation sociale. Le PNC prévoit par exemple la création de "mécanismes de participation et de représentation des communautés traditionnelles, indigènes et quilombolas ${ }^{39}$ notamment. Ceux-ci seront désormais impliqués dans l'élaboration, la mise en œuvre, le suivi, l'évaluation et la révision de politiques de protection et de promotion 
de leurs propres cultures $»^{40}$. Ainsi, ils obtiennent notamment : « une place privilégiée au sein des conseils de réflexion tenus par le ministère de la Culture ${ }^{41}$.»

C'est dans cette perspective d'implication des acteurs que nous repérerons une volonté institutionnelle de construire des acteurs engagés, plus à même de défendre leurs propres intérêts patrimoniaux. Sur le terrain, une personne responsable du département $d u$ Patrimoine immatériel au sein de l'Institut brésilien du patrimoine (IPHAN) évoque cette orientation, cette volonté de responsabilisation des acteurs sociaux, qu'elle estime partagée avec ces derniers. Notre interlocutrice nous rapporte alors l'intérêt et la perception de la sauvegarde, aux yeux des détenteurs et praticiens du patrimoine immatériel, tels qu'elle en perçoit leur représentation. En particulier, les actions de sauvegarde semblent envisagées comme une voie d'accès à l'autonomisation ${ }^{42}$, soit à une forme de mise en pouvoir ou mise en capacité des acteurs (du portugais empoderamento ou de l'anglais empowerment). À court terme, il s'agirait pour ces acteurs de mieux maîtriser les dispositifs patrimoniaux auxquels ils participent, et d'en assumer eux-mêmes la responsabilité et le contrôle : «Ce qui les intéresse [notamment], c'est de savoir comment rédiger eux-mêmes les rapports financiers qu'ils doivent nous remettre à la fin des projets conjoints, sans recourir à des intermédiaires pour cela. »

À plus long terme, le détenteur d'un patrimoine envisagerait notamment les dispositifs de sauvegarde comme le moyen d'accéder à une formation susceptible de renforcer ses capacités (du portugais capacitação) et ainsi, de se doter des moyens de prendre en charge son avenir patrimonial, des outils intellectuels de la gestion de son propre patrimoine de manière durable. Pour l'acteur, il s'agit non seulement de développer ses connaissances mais aussi d'acquérir une compétence critique, de manière à mieux maîtriser les enjeux politiques liés à la sauvegarde de son patrimoine. Ici, l'on repère combien l'acteur se donne les moyens de se construire en tant que sujet politique, compétent pour réfléchir avec ses partenaires institutionnels aux moyens et conditions de l'action patrimoniale. En d'autres termes, il s'engage dans un processus d'«alphabétisation patrimoniale», d'apprentissage $d u$ «langage patrimonial ${ }^{43}$ selon lequel il va se familiariser avec les dispositifs institutionnels du patrimoine et leur usage : repérer les appels à projets (editais ), savoir y répondre, gérer la relation aux agents et responsables institutionnels de ces appels, monter un projet, le mettre en œuvre et rédiger les rapports correspondants.

17 Ainsi, parallèlement à sa participation aux dispositifs patrimoniaux, il tendrait à investir le champ de l'éducation, de manière accroître sa capacité d'agir. Si l'acteur social recherche alors souvent l'accès à l'enseignement supérieur, par exemple, cette entreprise est désormais facilitée par la progressive ouverture des institutions à l'entrée à l'université de ces nouveaux étudiants, plus ou moins jeunes et au parcours parfois atypique. Nous citerons ici l'exemple éclairant d'un maitre capoeiriste, rencontré sur le terrain, dont la vaste expérience en tant que praticien de capoeira ${ }^{44}$ et détenteur d'un savoir à transmettre a été reconnue et validée au titre d'une équivalence universitaire. Celle-ci lui a ainsi permis d'accéder à l'université dans le cadre d'un doctorat en "Diffusion de la Connaissance", à l'université de Bahia (Universidade Federal da Bahia) (fig. 3). 
Figure 3

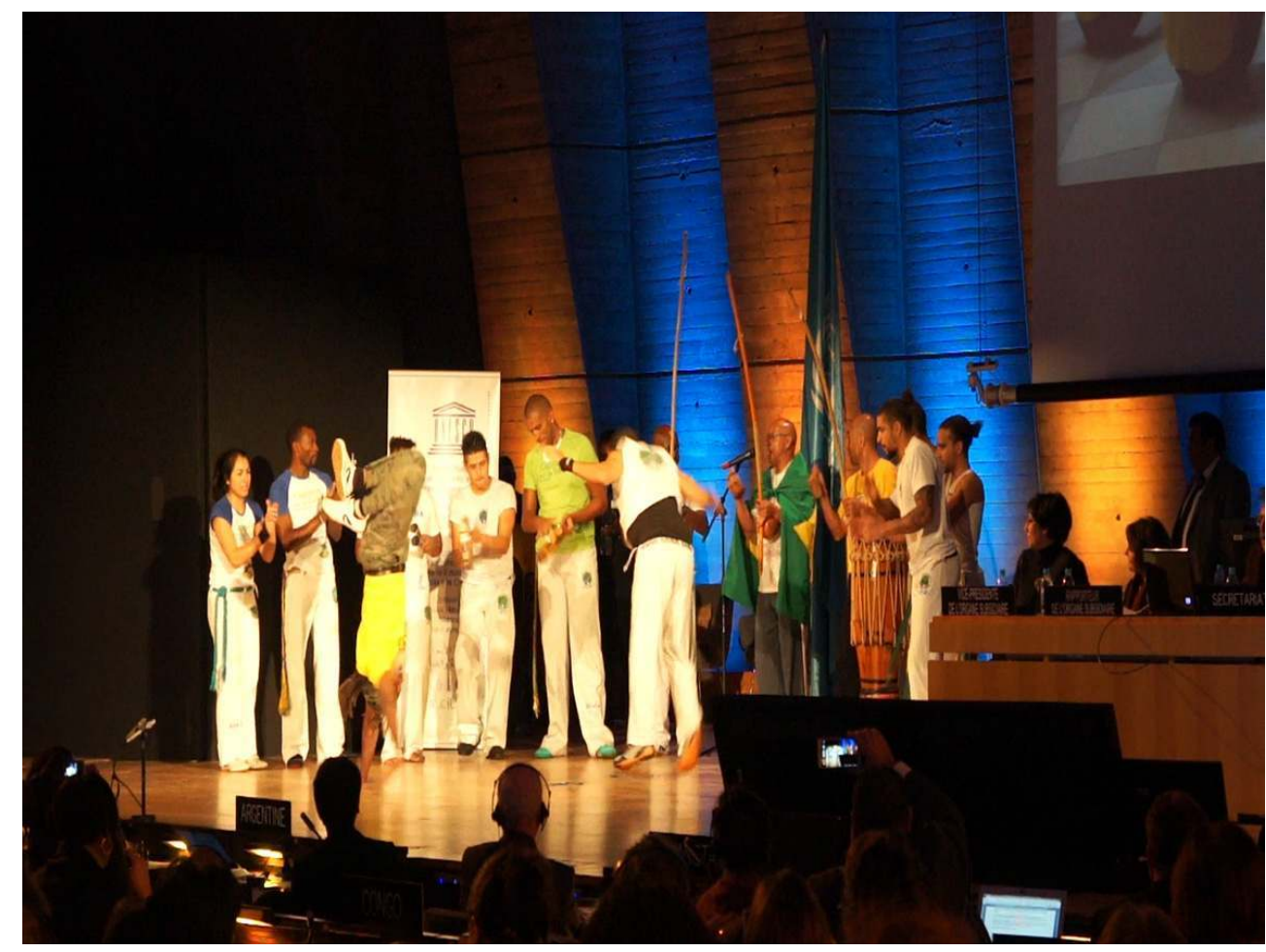

L'inscription de la « Roda de capoeira » comme patrimoine culturel immatériel de l'humanité lors de la 9e session du Comité Intergouvernemental pour la sauvegarde du patrimoine culturel immatériel, en novembre 2014 au siège de l'Unesco à Paris.

(c) Elaine Brito, 2014.

18 Cet exemple nous permet d'illustrer la manière dont les universités publiques brésiliennes s'emploient aujourd'hui à redresser une situation particulièrement inégalitaire en ce qui concerne l'accès à l'enseignement supérieur, jusqu'alors réservé aux classes sociales favorisées, en grande majorité blanches. Dans un pays où les Noirs et Métis représentent $50,1 \%$ de la population ${ }^{45}$, on mesure en effet un écart considérable en matière d'éducation : en 2010,31,1\% des étudiants de l'enseignement supérieur public étaient blancs, $12,8 \%$ noirs et $13,4 \%$ métis $^{46}$. Pour renverser cet état de fait, le gouvernement brésilien adoptait en août 2012 la loi $12.711^{47}$ visant à réserver aux populations noires, métisses et indigènes un quota de places à l'université. En vertu d'une telle politique de discrimination positive ${ }^{48}$, les universités et instituts d'enseignement supérieur publics se doivent désormais de proposer un contingent de $50 \%$ des places aux étudiants issus des lycées publics brésiliens de manière à recruter parmi les populations noires, métisses et indigènes.

Cet élargissement du recrutement permet ainsi d'ouvrir les portes de l'université aux groupes les plus socialement défavorisés, et notamment aux membres de groupes détenteurs d'un patrimoine immatériel, en grande majorité originaires des peuples afrobrésiliens et indigènes. À l'évidence, l'accès de ces populations à l'enseignement supérieur constitue un jalon important pour ces groupes qui entendent mettre à profit le complément de formation de leurs acteurs. L'exemple du maitre capoeiriste devenu doctorant nous permet également de percevoir la dynamique à l'œuvre selon laquelle l'acteur social du patrimoine met aujourd'hui en place de nouvelles stratégies, effectives, 
pour se former. Accédant désormais à l'université ou à des formations ponctuelles, il produit ainsi un discours semble-t-il toujours plus construit pour formuler ses propres demandes face aux institutions, ses propres réponses et ses propres actions patrimoniales. C'est ainsi qu'il se positionne de manière nouvelle en tant qu'expert scientifique de son patrimoine et accède aux moyens de sa propre gestion patrimoniale.

Ce faisant, l'acteur social acquiert également la capacité à mieux exprimer ses propres demandes de tous ordres. Ici, le lien entre la construction d'un sujet patrimonial et celle d'un sujet politique est clair. Pour notre interlocutrice au ministère, les demandes de sauvegarde que le département du Patrimoine immatériel reçoit sont selon elle ouvertement teintées d'une telle volonté de constitution de l'acteur social en tant que sujet politique. "Auparavant, on menait une politique de soutien liée à leurs besoins purement matériels (construction d'instrument, d'uniformes, du drapeau, etc.). Aujourd'hui cela n'est plus suffisant car les détenteurs exigent la mise en place d'autres actions politiques. »

Si ce type de demande émane ${ }^{49}$ des acteurs eux-mêmes, elle est accueillie, voire encouragée par l'institution, pour qui elle peut constituer l'une des visées mêmes de la sauvegarde: "Cette construction politique, nous la saisissons comme une action de sauvegarde».

Nous percevons bien ici la manière dont la politique patrimoniale s'est infléchie au cours des dernières années, pour venir recouvrir avec le concept de sauvegarde une conception plus large de l'action patrimoniale, incluant de nouveaux domaines d'action tels que la formation civique de l'acteur social. Il semble ainsi que l'action patrimoniale ne puisse aujourd'hui plus faire l'économie d'une intervention plus globale au niveau de l'acteur, tant l'on reconnaît que l'homme constitue le cœur, le socle et la matière première du patrimoine immatériel, dont il est finalement indissociable. Agir en faveur du patrimoine immatériel, ce serait donc nécessairement agir sur l'homme.

Ici, institutions et acteurs sociaux identifieraient donc la nécessité de faire également porter la sauvegarde sur l'homme lui-même, de sauvegarder le détenteur du patrimoine, et non plus son seul patrimoine. C'est de nouveau l'idée de reconnaitre combien la survie de l'homme, des hommes détenteurs d'un savoir traditionnel, conditionne la survie de la pratique elle-même. Comme nous l'indique une responsable de l'Institut brésilien du patrimoine (IPHAN) lors d'un entretien : «La sauvegarde est une opportunité que nous leur donnons [...] de se maintenir.»

En interrogeant sur le terrain des praticiens du jongo $0^{50}$, nous retrouvons ainsi ce rapport de l'action patrimoniale à la personne de l'homme lui-même. Pour l'un de nos enquêtés, la sauvegarde mériterait d'être non plus seulement celle de la pratique, mais surtout celle des praticiens eux-mêmes : «La sauvegarde du jongo, je pense que ne serait pas seulement la musique, elle devrait également s'appliquer aux maittres jongueiros. »

Dans le même sens, un autre enquêté précise que selon lui, l'attention devrait être recentrée sur le praticien et la sauvegarde agir sur l'acteur plutôt que sur l'objet patrimonial lui-même : "Vous n'avez pas besoin de vous inquiéter tant de la sauvegarde du jongo ici dans notre communauté, car le jongo ne va jamais mourir ici! [...] Ce dont il faut s'inquiéter, c'est de la sauvegarde des jongueiros!» (fig. 4). 
Figure 4

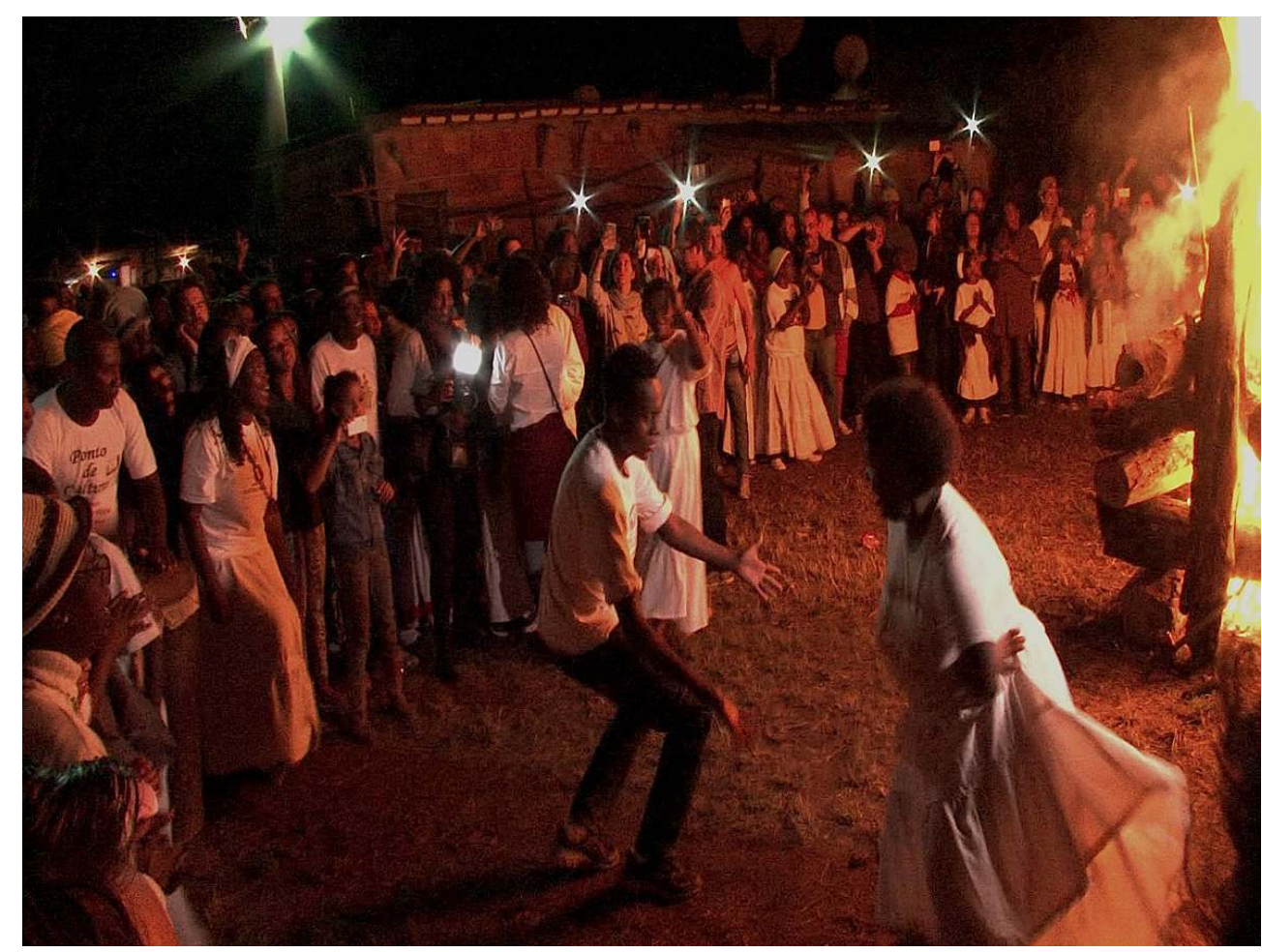

La pratique du jongo, lors de la fête du « preto velho » au Quilombo São José da Serra, dans la commune de Valença, région de Rio de Janeiro.

(C) Elaine Brito, 2015.

Ici, la sauvegarde de l'homme n'est plus directement au service de la sauvegarde de la pratique, mais elle semble en faire partie intégrante, voire la dépasser : l'acteur social semble considérer que son bien-être socio-économique constitue une priorité et relève des compétences de l'institution patrimoniale. On comprend ici combien l'action patrimoniale n'est plus nécessairement conditionnée par la peur de la perte $^{51}$ : le patrimoine n'est pas ici en danger, en revanche l'action patrimoniale se doit, malgré tout, de contribuer au bien-être socio-économique des praticiens et ainsi, de leur offrir les conditions de la pratiquer de manière vivante et créative.

\section{La sauvegarde patrimoniale comme levier socio- économique}

Dans ces derniers témoignages, l'on comprend combien, pour l'acteur social, la sauvegarde pourrait s'étendre au champ socio-économique : il s'agirait de lui garantir des conditions de vie décentes, afin de lui permettre de pratiquer son art et ainsi de le perpétuer.

Le Programme national du patrimoine immatériel (PNPI) prévoit d'ailleurs une composante sociale ${ }^{52}$, suivant cette idée d'offrir au détenteur de telles conditions de vie, propices à la pratique de leurs expressions culturelles ${ }^{53}$. LE PNPI offre ainsi aux individus issus de groupes culturels défavorisés de bénéficier désormais de ressources fédérales à cet effet $^{54}$. Parallèlement, le PNPI prévoit également de soutenir les projets locaux de 
développement socio-économique qui incluent un travail de valorisation du patrimoine immatériel des populations visées. Enfin, les subventions accordées au groupe ${ }^{55}$ pour mener à bien des initiatives de sauvegarde sont susceptibles de générer un revenu, si maigre soit-il, pour la communauté. On pensera par exemple aux bourses versées aux participants indigènes d'un projet d'inventaire du patrimoine immatériel, rémunérés pour leur travail de recherche, ou bien aux produits de type CD, DVD ou livre issus des mêmes projets de documentation du patrimoine immatériel soutenus par le ministère et dont un certain nombre d'exemplaires seront mis à disposition des communautés pour la vente au grand public.

Le Programme national de la culture (PNC) dont nous avons déjà parlé se prononce également en ce sens lorsqu'il entend offrir une "protection financière aux détenteurs des savoirs issus des cultures populaires et traditionnelles ». C'est l'idée que, « citoyens comme les autres, les individus reconnus détenteurs de ces pratiques requièrent des conditions de vie décentes ». Or, «de nombreux détenteurs brésiliens, jeunes ou plus âgés, vivent en situation de précarité et sont exposés à un risque social [...]. Appliquée à cette population, la protection sociale constitue d'ailleurs l'une des actions importantes engagées en faveur de la valorisation et de la sauvegarde des expressions et des connaissances populaires et traditionnelles ${ }^{56}$.

La politique patrimoniale de la sauvegarde est alors formulée pour s'intégrer à un ensemble plus large dont la cohérence repose sur sa visée commune: le développement humain, lui-même décliné en quatre pôles : éducation, santé, économie et culture. C'est l'idée que le patrimoine immatériel se doit, lui aussi, d'agir en faveur du développement des communautés. «On met ici en avant une conception plus large et diversifiée de "bien culturel" [qui] comprend la culture comme facteur de développement économique et social $^{57}$.»

\section{Le patrimoine immatériel, instrument de revendication de droits}

31 Ces réflexions prennent un sens tout particulier au Brésil, un pays dans lequel les inégalités sociales demeurent considérables et affectent particulièrement un certain nombre de communautés détentrices d'un patrimoine immatériel reconnu comme patrimoine immatériel national ou en voie de reconnaissance. En effet, au Brésil, la grande majorité des pratiques vivantes faisant l'objet d'une attention dans le cadre du PNPI sont issues des groupes indigènes ou afro-brésiliens vivant en situation de précarité, d'exclusion sociale ou héritiers d'une histoire collective douloureuse. Ici, « les actions de sauvegarde du patrimoine immatériel encouragent la visibilité et l'auto-estime des groupes sociaux historiquement écartés des espaces politiques et contribuent, ainsi, à soutenir leur demandes de droits ${ }^{58}$. Ici, l'idée de sauvegarde serait avant tout celle qui accorde au détenteur du patrimoine la possibilité de le façonner comme il l'entend, afin de revendiquer le droit le plus élémentaire : « le droit d'avoir des droits » ${ }^{59}$. C'est donc en tant que dispositif mis à profit pour soutenir la revendication de droits sociaux, politiques et culturels de groupes minoritaires que le patrimoine semble envisagé par les acteurs sociaux : comme un moyen d'accéder à la reconnaissance sociopolitique, ou encore une plateforme susceptible de donner un écho nouveau à des revendications anciennes. Enfin, l'attribution du statut patrimonial signale pour eux l'obtention d'une reconnaissance fortement symbolique, voire une forme de réparation vis-à-vis de préjudices 
historiquement subis. Comme nous l'explique un praticien du jongo sur le terrain : "Le titre que nous avons reçu en tant que patrimoine immatériel brésilien, je le compare avec la Loi impériale d'abolition de l'esclavage. Les Noirs ont ressenti le besoin de dire : “je suis là", et de montrer la raison de ce "je suis là". Ce Registro, c'est la même chose. » (fig. 5)

Figure 5

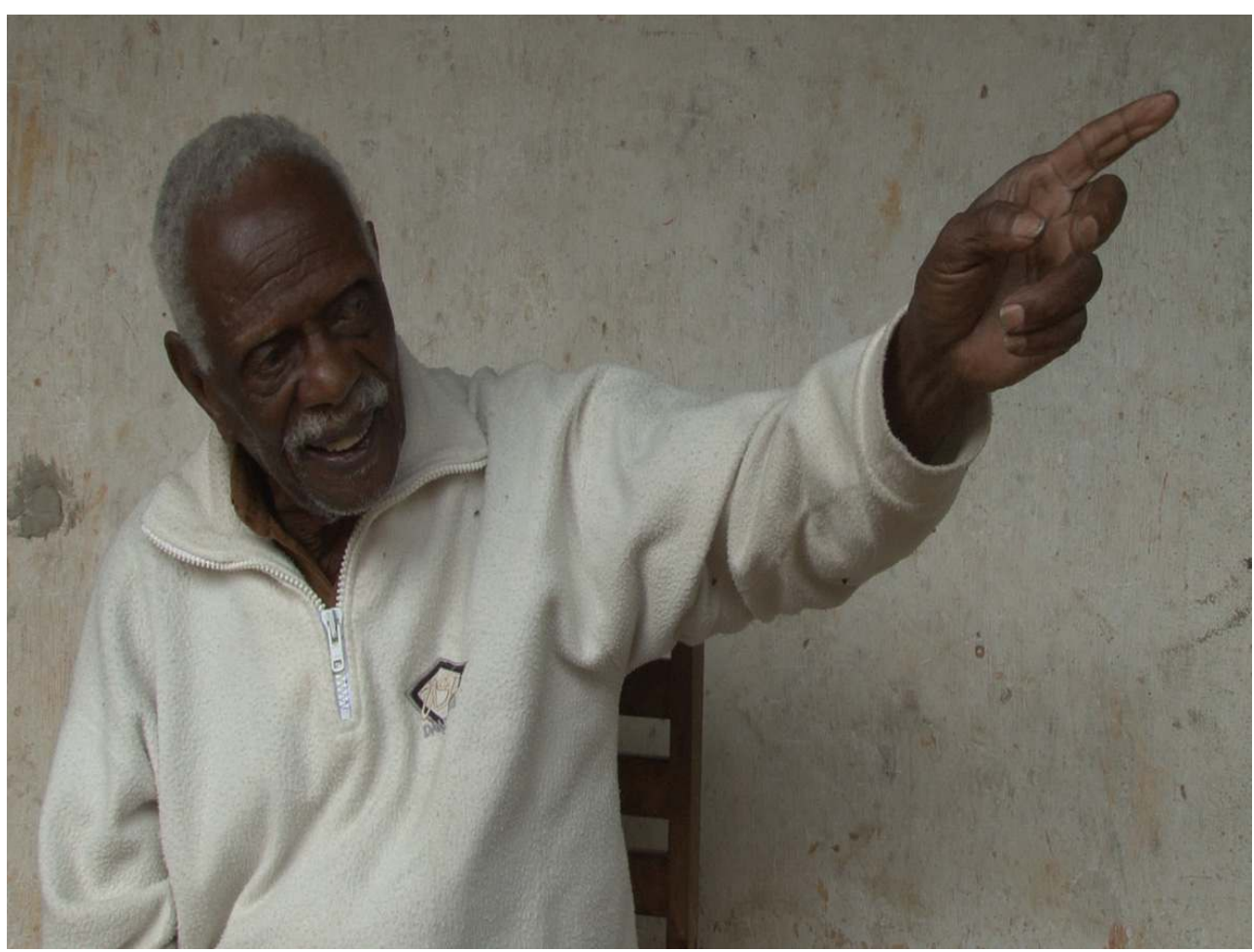

Manuel Seabra, plus ancien maître jongueiro du Quilombo São José da Serra, dans la commune de Valença, région de Rio de Janeiro.

(c) Elaine Brito, 2015.

Ainsi, l'obtention d'une inscription au titre de patrimoine immatériel aurait la capacité à rendre visibles les communautés effacées et pourrait contribuer à officialiser une légitimation largement attendue.

Ici, l'on comprend la force symbolique du titre mais également du concept de patrimoine immatériel au Brésil tant « il suppose l'implication des groupes humains dans l'étude et la protection du patrimoine, et peut constituer un moyen de prévenir ou de traiter les possibles "émotions patrimoniales ${ }^{60}$ " nées d'interventions perçues comme brutales ou inadéquates [...] ». Le concept de patrimoine immatériel, ainsi que le dispositif qui l'accompagne auraient ainsi la vertu de traiter de manière apaisée, voire cathartique, des histoires douloureuses et permettre une forme de reconnaissance contemporaine, d'acceptation, possiblement réparatrice ou réconciliatrice.

\section{Conclusion : Un patrimoine centré sur la sauvegarde de l'individu}

Le tournant du XXI ${ }^{e}$ siècle semble ainsi marqué par une volonté législative de proposer des programmes destinés à construire l'acteur social en tant que sujet politique et l'on voit 
donc combien ce dernier se voit progressivement placé au centre de la politique patrimoniale brésilienne à travers ceux-ci. Il s'agit de doter l'acteur social des moyens juridiques de s'exprimer au sujet des textes de loi, voire de les contester comme nous l'avons vu, mais aussi de lui fournir les moyens techniques (sous la forme de dispositifs, programmes ou projets appelant sa participation), et intellectuels (sous la forme de formations ponctuelles ou universitaires) et économiques (sous forme de subventions), d'y contribuer.

C'est dans cette optique que l'État brésilien soutient désormais les initiatives concrètes en faveur du patrimoine immatériel ${ }^{61}$, proposées ou mises en œuvre en partenariat avec les groupes dont il émane. En leur offrant l'accompagnement et les moyens de réaliser ces initiatives, il tente d'accéder aux besoins de l'acteur social en la matière et bien au-delà. Ce nouveau positionnement de l'État, cet engagement en faveur de l'acteur social, semble$\mathrm{t}$-il, marquera la décennie dans le domaine du patrimoine immatériel : pour certains, ce serait même la grande conquête des années 2000, directement issue de la Constitution qui la prévoyait, et finalement venue à maturation quelque quinze ans plus $\operatorname{tard}^{62}$.

Si les dispositifs de sauvegarde de l'immatériel touchent ici en principe à la sphère patrimoniale, nous comprenons également leur résonance, plus large et assumée comme telle : l'action patrimoniale a ici la capacité de rejaillir sur l'ensemble de la vie publique et sociale. Nous envisageons alors déjà l'idée d'un patrimoine comme un agent déclencheur, susceptible d'étendre la participation sociale et d'affecter ainsi les sphères politique, économique et sociale de la vie des groupes. Nous avons d'ailleurs expliqué combien, pour les groupes eux-mêmes, l'action patrimoniale pouvait servir de relais, voire de tremplin à leurs revendications en termes de droits sociopolitiques.

En effet, l'idée de la sauvegarde patrimoniale, à travers la politique de l'immatériel et les dispositifs qui la mettent en œuvre, viserait au Brésil bien plus que son propre objet, soit le maintien et la vitalité de pratiques traditionnelles. Pour réaliser ce dernier objectif, elle se dépasserait elle-même et toucherait à plusieurs domaines de la vie publique. Elle tendrait ainsi à procurer aux groupes détenteurs d'un patrimoine les moyens de vivre décemment, de manière à mieux les impliquer dans le travail patrimonial et la poursuite de ses objectifs. Ainsi, au Brésil, la sauvegarde aurait pour ambition avant tout la formation de l'acteur social en tant que sujet politique: il s'agirait de le mettre en capacité d'agir, d'améliorer par ses propres moyens son environnement socioéconomique au quotidien, et incidemment, de nourrir et perpétuer sa pratique culturelle. Pour les institutions patrimoniales brésiliennes, la transformation de l'acteur en tant qu'être politique semble ici être la condition sine qua non de la transmission d'un savoirfaire et ultimement, de la sauvegarde d'un patrimoine immatériel.

Selon ce mode opératoire, la sauvegarde patrimoniale aurait bien pour objet premier la sauvegarde de l'acteur social, détenteur du patrimoine, qu'elle rechercherait avec lui et pour lui : la sauvegarde ne serait pas directement liée à l'objet patrimonial, mais bien au détenteur lui-même, en vue, bien entendu, de poursuivre indirectement la sauvegarde de sa pratique.

Pourtant, si les institutions s'emploient, semble-t-il, à promouvoir la sauvegarde de l'individu, il ne s'agirait pas pour autant d'un seul prétexte pour servir, en définitive, le patrimoine. L'action sociale ne serait pas un détour, aussi essentiel qu'il paraisse, au service du patrimoine. Au contraire, ces réflexions nous montrent bien la manière dont le patrimoine s'inscrit dans un ensemble plus large et ne peut se concevoir seul : il fait 
aujourd'hui au Brésil partie d'un écosystème politico-socio-économique et poursuit avant tout un objectif fondamental de développement humain.

\section{BIBLIOGRAPHIE}

ABREU, Regina. « Patrimonialisation des différences et nouveaux sujets de droit collectif au Brésil », pp. 69-98. In : TARDY, C. (Org.) ; DODEBEI, V. (Org.), Mémoire et nouveaux patrimoines, Marseille : OpenEdition Press, 2015.

ABREU, Regina. “Dinámicas de Patrimonialización y comunidades tradicionales en Brasil”, dans : Chaves, Margarita; Montenegro, Maurício; Zambrano, Marta. (Org.). El valor del Patrimonio: mercado, politicas culturales y agenciamientos sociales. 1ed.Bogotá: ICANH, 2013.

ABREU, Regina. « A patrimonialização das diferenças : usos da categoria », dans Inovação Cultural, Patrimônio e Educação. 1ed. éd., p. 65-79. Recife: Massangana, 2010.

ARAÚJO, José Cordeiro de ; PEREIRA JÚNIOR, José de Sena; PEREIRA, Lúcio Soares; RODRIGUES, Ricardo José Pereira (Org.). "Ensaios sobre impactos da Constituição Federal de 1988 na sociedade brasileira”. Brasília: Centro de Documentação e Informação, 2008.

CARNEIRO DA CUNHA, Manuela. “Conversa com Manuela Carneiro da Cunha”, pp. 375, dans CARNEIRO DA CUNHA, Manuela, Cultura com aspas e outros ensaios. São Paulo : Cosac \& Naif, 2009.

DA SILVA SANTOS, Giordanna Laura. «"Novos” atores sociais nas Políticas Culturais: Uma análise da participação política da esfera civil no Colegiado Setorial de Culturas Populares do Ministério da Cultura (MinC) ». Araraquara - SP, 2013.

DELGADO, Lucilia de A.N.. “A Campanha das Diretas Ja : narrativas e memorias”, São Leopoldo, XXIV Simposio Nacional de Historia, 2007.

GALLOIS, Dominique (Org.). Patrimônio cultural imaterial e povos indígenas, São Paulo, Iepé, 2006.

GUIMARÃES, Ulysses. Discours prononcé par le Président de l'Assemblée National Constituante au Brésil, 1988. Disponible en : http://www2.camara.leg.br/camaranoticias/radio/materias/CAMARA-EHISTORIA/339277--INTEGRA-DO-DISCURSO-PRESIDENTE-DA-ASSEMBLEIA-NACIONALCONSTITUINTE,--DR.-ULISSES-GUIMARAES-\%2810-23\%29.html - Dernière consultation le 23 juillet 2015.

HOTTIN, Christian. « Sept ans l'âge de raison. Dynamiques et enjeux du patrimoine culturel immatériel », Le patrimoine culturel. Premières expériences en France, Paris et Arles, Maison des cultures du monde et Actes sud, 2011, (collection « Internationale de l'imaginaire, n.s., numéro 21) 365 p., p. 27-57.

HOTTIN, Christian. « Anti-monumental ? Actualité du patrimoine culturel immatériel ». Monumental, semestriel n ${ }^{\circ}$ : 26-29, 2008.

JADÉ Mariannick, Patrimoine immatériel : perspectives d'interprétation du concept de patrimoine, Paris, L'Harmattan, 2006. 
JELIN, Elizabeth, « Exclusión, memorias y luchas políticas ». In Cultura, política y sociedad Perspectivas latinoamericanas, 219-39. Ciudad Autónoma de Buenos Aires, Argentina: CLACSO, Consejo Latinoamericano de Ciencias Sociales, 2005.

KLEBA, Maria Elizabeth \& WENDAUSEN, Agueda, « Empoderamento: processo de fortalecimento dos sujeitos nos espaços de participação social e democratização politica », pp.733-743, Saude e Sociedade, São Paulo, v.18, 2009.

FONSECA, Maria Cecilia Londres, «La sauvegarde du patrimoine culturel immatériel au Brésil : définitions et principes, législation, instruments, défis ", pp. 79-86, dans GAUTHIER, Antoine, Les mesures de soutien au patrimoine immatériel [en ligne], actes du colloque, avril 2011, Québec, Conseil québécois du patrimoine vivant, 2012. Disponible sur : http://patrimoinevivant.qc.ca/wpcontent/uploads/2009/10/Les-mesures-de-soutien-au-patrimoine-immateriel-actes-ducolloque-2011.pdf, consulté le 23 juillet 2015.

MONTEIRO, Elaine, "Educação popular e politica cultural: desafios do "outro" como sujeito da politica”, dans 36ème Reunião Nacional da ANPEd. Goiânia, 2013.

MONTEIRO, Elaine \& SACRAMENTO, Mônica P., « Pontão de Cultura de bem registrado e salvaguarda de Patrimônio Imaterial: a experiência do Jongo no Sudeste », dans Políticas culturais: teorias e práxis. Rio de Janeio, Brasil: Universidade Federal Fluminense, 2010.

PECKHAM, R.S. (ed.), 2003, Rethinking Heritage. Cultures and Politics in Europe, London: I.B. Tauris.

ROCHA, Enid, « A Constituição Cidadã e a institucionalização dos espaços de participação social: avanços e desafios » [en ligne], pp. 131, dans 20 anos da Constituição Cidadã : avaliaçao e desafio da seguridade Social, 2008. Disponible sur : http://www.ipea.gov.br/participacao/images/pdfs/ participacao/outras_pesquisas/a\%20constituio\%20cidad\%20e\%20a\%20institucionalizao\%20dos\% 20espaos\%20de\%20participao\%20social.pdf, consulté le 30 juillet 2015.

SANT'ANNA, Marcia, «A face imaterial do patrimônio cultural: os novos instrumentos de reconhecimento e valorização ", dans ABREU, R. M. R. M. ; CHAGAS, M. S., Memória e Patrimônio : ensaios contemporâneos. Rio de Janeiro: DP\&A editora Ltda, 2003, v. 1

TARDY, Cécile \& DODEBEI, Vera, dir., Mémoire et nouveaux patrimoines, sélectionné dans le cadre de l'appel à projets 2010 Saint-Hilaire ( $\left.n^{\circ} 06 / 2011\right)$, Université Fédérale de l'Etat du Rio de Janeiro - UNIRIO, 2015.

TURATTI, Maria Cecília Manzoli \& GODOY, Clayton Franco de, «Cultura: Acarajé com mais recheio : Primeiro Conceito », São Paulo, 2011.

Textes légaux et législatifs

Constitution brésilienne de 1988 : Traduction : Jacques Villemain, Jean François Cleaver. Brasília 1998 : http://www.wipo.int/wipolex/fr/text.jsp?file_id=218254 - Dernière consultation le 23 juillet 2015.

Carta de Fortaleza, 1997: http://portal.iphan.gov.br/uploads/ckfinder/arquivos/Carta\%20de\% 20Fortaleza\%201997.pdf - dernière consultation le 20 juillet 2015

IPHAN, Departamento de Identificação e Documentação - MinC, Inventário Nacional de Referências Culturais : http://portal.iphan.gov.br/uploads/ckfinder/arquivos/ Manual_do_INRC.pdf - Dernière consultation le 10 août 2015.

Plano Nacional Patrimônio Imaterial (PNPI), 2000 : http://portal.iphan.gov.br/pagina/ detalhes/761/ - Dernière consultation le 20 juillet 2015. 
PNPI, 2000, lignes d'action : http://portal.iphan.gov.br/pagina/detalhes/857/ - Dernière consultation le 5 août 2015.

IBGE : http://www.censo2010.ibge.gov.br/ Dernière consultation le 10 septembre 2015.

Loi 12.711, de 29 août 2012 : http://www.planalto.gov.br/ccivil_03/_ato2011-014/2012/lei/

112711.htm - Dernière consultation le 10 septembre 2015

\section{NOTES}

1. - Elaine Brito est doctorante, financée par la fondation Capes (ministère de l'Éducation brésilien). Doctorat en cours en sciences de l'information et de la communication, programme Culture, Patrimoine, Mémoire, au sein de l'équipe Culture et Communication du Centre Norbert Elias, université d'Avignon et des Pays de Vaucluse (UAPV-France). Cotutelle avec le doctorat Estudos Interdisciplinares em Memoria Social, programme Memória e Patrimônio, université de Rio de Janeiro (UNIRIO), Brésil. Nolwenn Pianezza est doctorante contractuelle chargée d'enseignement à l'université d'Avignon et des Pays de Vaucluse (UAPV), France. Doctorat en cours en sciences de l'information et de la communication, programme Culture, Patrimoine, Mémoire, au sein de l'équipe Culture et Communication du Centre Norbert Elias, université d'Avignon et des Pays de Vaucluse (UAPV), France. Cotutelle avec le doctorat Estudos Interdisciplinares em Memoria Social, programme Memória e Patrimônio, université de Rio de Janeiro (UNIRIO), Brésil.

2. - Entretiens réalisés avec une série d'acteurs institutionnels - décideurs, ministère de la Culture (MinC), Institut du patrimoine historique et artistique national (IPHAN) et d'acteurs sociaux, issus de la société civile - membres d'associations de praticiens ou détenteurs individuels d'un patrimoine immatériel.

3. - Il est à préciser que ce texte a été finalisé et remis pour publication en octobre 2015. Le panorama réalisé couvre donc la période citée, jusqu'à cette date.

4. - ABREU, Regina. "Patrimonialisation des différences et nouveaux sujets de droit collectif au Brésil ». Dans TARDY, Cécile, DODEBEI, Vera (dir.). Mémoire et nouveaux patrimoines. Marseille : OpenEdition Press, 2015, p. 69-98.

5. - « Des élections directes, maintenant !».

6. - DELGADO, Lucilia de Almeida Neves. «A Campanha das Diretas Ja : narrativas e memorias». Dans XXIV Simposio Nacional de Historia, São Leopoldo, 2007. São Leopoldo : Unisinos, 2007, p. 413.

7. - Ibid., p. 419.

8. - Ibid.

9. - ROCHA, Enid. «A Constituição Cidadã e a institucionalização dos espaços de participação social: avanços e desafios » [en ligne]. Dans 20 anos da Constituição Cidadã : avaliaçao e desafio da seguridade Social, 2008, p. 131. Voir sur le site : http://www.ipea.gov.br/participacao/images/ pdfs/participacao/outras_pesquisas/a\%20constituio\%20cidad\%20e\%20a\%20institucionalizao\% 20dos\%20espaos\%20de\%20participao\%20social.pdf [consulté le 30/07/2015].

10. - «LXXIII - “Tout citoyen peut légitimement intenter une action populaire aux fins d'annulation d'un acte lésant le patrimoine public, celui d'une entité à laquelle l'État participe, la morale administrative, l'environnement ou le patrimoine historique ou culturel». Texte constitutionnel du 5 octobre 1988. Traduction : Jacques Villemain, Jean François Cleaver. Brasília, 1998. http://www.wipo.int/wipolex/fr/text.jsp?file_id=218254 [consulté le 23/07/2015].

11. - Discours prononcé par le président de l'Assemblée nationale constituante, Ulysses Guimaraes, lors de la cérémonie de promulgation de la Constitution fédérale de 1988. Voir le site : http://www2.camara.leg.br/camaranoticias/radio/materias/CAMARA-E-HISTORIA/339277-- 
INTEGRA-DO-DISCURSO-PRESIDENTE-DA-ASSEMBLEIA-NACIONAL-CONSTITUINTE,--DR.-ULISSESGUIMARAES-\%2810-23\%29.html [consulté le 23/07/2015].

12. - Ibid.

13. - CARNEIRO DA CUNHA, Manuela. «Conversa com Manuela Carneiro da Cunha ». Dans Ead. Cultura com aspas e outros ensaios. São Paulo : Cosac \& Naif, 2009, p. 375.

14. - Extrait de la Constitution fédérale brésilienne de 1988, art. 216. "Les biens de nature matérielle ou immatérielle, pris individuellement ou ensemble, porteurs de références à l'identité, l'action et la mémoire des différents groupes formant la société brésilienne constituent le patrimoine culturel brésilien ». Voir le site: http://www.wipo.int/wipolex/fr/text.jsp? file_id=218254 [consulté le 23/07/2015].

15. - ABREU, Regina. «A patrimonialização das diferenças : usos da categoria ». Dans Inovação Cultural, Patrimônio e Educação. Recife : Massangana, 2010, p. 65-79.

16. - GALLOIS, Dominique (dir.). Patrimônio cultural imaterial e povos indígenas. São Paulo : Iepé, 2006, p. 21.

17. - FONSECA, M. C. L. «La sauvegarde du patrimoine culturel immatériel au Brésil : définitions et principes, législation, instruments, défis ». Dans GAUTHIER, Antoine. Les Mesures de soutien au patrimoine immatériel [en ligne], actes du colloque, avril 2011. Québec: Conseil québécois du patrimoine vivant, 2012, p. 79-86, ici p. 82. Voir sur le site : http://patrimoinevivant.qc.ca/wpcontent/uploads/2009/10/Les-mesures-de-soutien-au-patrimoine-immateriel-actes-ducolloque-2011.pdf [consulté le 23/07/2015].

18. - Ibid.

19. - Cette traduction est également adoptée par M. C. L. Fonseca.

20. - SANT'ANNA, Marcia. "A face imaterial do patrimônio cultural: os novos instrumentos de reconhecimento e valorização ». Dans ABREU, R. M., CHAGAS, Mario. Memória e Patrimônio : ensaios contemporâneos. Rio de Janeiro : DP \& A/Faperj/Unirio : 2003, v. 1.

21. - GALLOIS, D. Op. cit., p. 24.

22. - Ibid., p. 72.

23. - Pour M. C. L. Fonseca, il s'agit du «folklore » et des « cultures populaires » (FONSECA, M. C. L. Art. cit.).

24. - FONSECA, M. C. L. Dans IPHAN. Departamento de Identificação e Documentação - MinC, Inventário Nacional de Referências Culturais: http://portal.iphan.gov.br/uploads/ckfinder/ arquivos/Manual_do_INRC.pdf - [consulté le 10/08/2015].

25. - FONSECA, M. C. L. « La sauvegarde du patrimoine culturel immatériel au Brésil... ». Art. cit., p. 81-82.

26. - Ibid. ; cité par M. C. L. Fonseca dans son texte de 2012, à partir de : FONSECA, M. C. L., "Referências culturais: base para novas políticas de patrimônio ». Dans Manual de aplicação do INRC. Brasília : Iphan/DID, 2000, p. 11.

27. - Ibid.

28. - HOTTIN, Christian. «Sept ans, l'âge de raison. Dynamiques et enjeux du patrimoine culturel immatériel ». Dans Le Patrimoine culturel. Premières expériences en France. Paris/Arles : Maison des cultures du monde/Actes Sud, coll. « Internationale de l'imaginaire », 2011, p. 27-57.

29. - Séminaire tenu à Fortaleza du 10 au 14 novembre 1997.

30. - Lettre de Fortaleza, 1997 http://portal.iphan.gov.br/uploads/ckfinder/arquivos/Carta\% 20de\%20Fortaleza\%201997.pdf [consulté le 23/07/2015].

31. - Professionnels du patrimoine et acteurs sociaux.

32. - MONTEIRO, Elaine. «Educação popular e politica cultural: desafios do "outro" como sujeito da politica ». Dans 36e Reunião Nacional da ANPED. Goiânia : 2013.

33. - Carta (Charte ?) de Fortaleza, 1997, p. 2.

34. - Désignant à la fois l'acte (d'inscription) et la liste d'inscription (du registre) au titre de patrimoine immatériel du Brésil. 
35. - GALLOIS, D. Op. cit., p. 72.

36. - PNPI, 2000, lignes d'action: http://portal.iphan.gov.br/pagina/detalhes/857/ [consulté le 05/08/2015]

37. - SANT'ANNA, M. Art. cit.

38. - PNPI, 2000.

39. - Juridiquement, les Quilombolas ou Quilombos désignent les communautés noires rurales qui se sont constituées dans le temps, notamment à travers les fuites et occupations de terres libres et isolées, mais, également, à travers l'héritage, le don ou l'achat de terres, antérieurement ou postérieurement à l'abolition de l'esclavage. http://www.planalto.gov.br/ccivil_03/ decreto/2003/d4887.htm [consulté le 20/08/2015].

40. - DA SILVA SANTOS, Giordanna Laura. " "Novos" atores sociais nas Políticas Culturais: Uma análise da participação política da esfera civil no Colegiado Setorial de Culturas Populares do Ministério da Cultura (MinC)». Anais do Incontro Internacional Partiçipao, Democracias Publicas. Aproximando agendas e agentes, 2013, v. 1.

41. - Entretien au ministère de la Culture.

42. - Le terme empoderamento, fréquemment employé au Brésil, est ici compris comme un "processus de renforcement des acteurs dans les espaces de participation sociale et démocratisation politique " (KLEBA, Maria Elizabeth, WENDAUSEN, Agueda. « Empoderamento : processo de fortalecimento dos sujeitos nos espaços de participação social e democratização politica". Saude e Sociedade, v. 18, 2009, p. 733-743).

43. - ABREU, R. « Dinámicas de Patrimonialización y comunidades tradicionales en Brasil ». Dans CHAVES, Margarita, MONTENEGRO, Maurício, ZAMBRANO, Marta (dir.). El valor del Patrimonio: mercado, politicas culturales y agenciamientos sociales. Bogotá : ICANH, 2013.

44. - Reconnu comme un art martial afro-brésilien, la capoeira associe le corps, la musique et les chants. Depuis 2014, la capoeira intègre la Liste représentative du Patrimoine culturel immatériel de l'Humanité de l'Unesco.

45. - IBGE: http://www.censo2010.ibge.gov.br/ [consulté le 10/09/2015]. Source: http:// www.censo2010.ibge.gov.br/ [consulté le 16/07/2015].

46. - Ibid.

47. - Source: http://www.planalto.gov.br/ccivil_03/_ato2011-2014/2012/lei/l12711.htm [consulté le 16/07/2015].

48. - Avec la législation 12.711 , entrée en vigueur en août 2012, le ministère de l'Éducation du gouvernement brésilien entend mettre en œuvre une politique d'action affirmative. http:// www.ebc.com.br/educacao/2012/10/entenda-a-lei-de-cotas-nas-universidades-federais [consulté en $08 / 2015]$.

49. - Et doit émaner des acteurs eux-mêmes, selon notre interlocutrice : « Nous veillons à ce que la demande vienne des groupes eux-mêmes. »

50. - Le jongo, danse au son des tambours et chants, fait partie de la culture afro-brésilienne et a considérablement influencé la formation de la samba et de la culture populaire brésilienne. Cette pratique est reconnue en tant que patrimoine immatériel du Brésil depuis septembre 2005. Voir le site : http://portal.iphan.gov.br/pagina/detalhes/59 [consulté en 07/2015].

51. - PECKHAM, Robert Shannan (éd.). Rethinking Heritage. Cultures and Politics in Europe. Londres/ New York: I. B. Tauris, 2003; JADÉ, Mariannick. Le Patrimoine immatériel: perspectives d'interprétation du concept de patrimoine. Paris : L'Harmattan, 2006 ; «La peur de la perte est ce qui donne naissance aux instruments de sanctification et de préservation » (PECKHAM, R.S. Op. cit.).

52. - « Les directives du PNPI prévoient la promotion de l'inclusion sociale et de conditions de vie décentes des producteurs et détenteurs du patrimoine culturel immatériel, et favorisent la participation des groupes qui produisent et transmettent les manifestations culturelles de nature immatérielle dans les projets de préservation et valorisation de ce patrimoine ». Voir le site : http://portal.iphan.gov.br/pagina/detalhes/761/ [consulté le 16/08/2015]. 
53. - Voir le site : http://portal.iphan.gov.br/pagina/detalhes/761/ [consulté le 16/08/2015].

54. - Monteiro, 2013.

55. - [...] ou bien aux relais scientifiques accompagnant les groupes de manière partenariale.

56. - Metas do Plano Nacional da Cultura, 2011; Plano Nacional da Cultura: http:// pnc.culturadigital.br/metas/politica-nacional-de-protecao-e-valorizacao-dos-conhecimentos-eexpressoes-das-culturas-populares-e-tradicionais-implantada/ [consulté le 20/07/2015].

57. - FONSECA, M. C. L. Art. cit., p. 81.

58. - TURATTI, Maria Cecília Manzoli, GODOY, Clayton Franco de. «Cultura: Acarajé com mais recheio : Primeiro Conceito ». São Paulo : Escala, 2011.

59. - JELIN, Elizabeth. «Exclusión, memorias y luchas políticas». Dans MATO, Daniel (éd.). Cultura, política y sociedad Perspectivas latinoamericanas. Buenos Aires: CLACSO (Consejo Latinoamericano de Ciencias Sociales), 2005, p. 219-239.

60. - C. HOTTIN (art. cit., p. 22) évoque des «émotions patrimoniales nées d'interventions perçues comme brutales ou inadéquates sur les monuments liés à l'identité d'une collectivité ». Si ici, nous faisons référence à un contexte plus large d'histoires douloureuses, de violences, spoliation et servitude vis-à-vis de plusieurs communautés brésiliennes, il nous a semblé pertinent de transposer cette formule à notre contexte, tant elle nous permet de percevoir la nature particulièrement sensible des questions patrimoniales contemporaines lorsqu'elles sont appliquées à de tels groupes héritiers d'une histoire traumatique. Ici, le patrimoine deviendrait un enjeu capable à la fois de cristalliser des tensions historiques et de contribuer à les résoudre, ou pour ce dernier point, c'est du moins le potentiel qu'il semble revêtir pour les différents acteurs. L'on se demande alors si, pour l'État brésilien, l'attention qu'il accorde aux communautés traditionnelles ne serait pas teintée d'une forme de culpabilité et d'une volonté de venir réparer certains torts subis. De la même manière que le patrimoine immatériel serait né d'un désir de rééquilibrage Nord-Sud à l'échelle internationale, il pourrait au Brésil correspondre à une volonté de redresser une situation inégalitaire à l'intérieur du pays lui-même.

61. - L'on rappellera ici qu'il s'agit d'actions d'identification, d'inventaire, de registre et de sauvegarde du patrimoine immatériel.

62. - MONTEIRO, Elaine, SACRAMENTO, Mônica P. «Pontão de Cultura de bem registrado e salvaguarda de Patrimônio Imaterial: a experiência do Jongo no Sudeste ». Dans AZEVEDO, Lia Calabre (éd.). Políticas culturais: teoria e práxis. Sao Paulo/Rio de Janeio : Itau Cultural/Casa de Rui Barbosa, 2011.

\section{RÉSUMÉS}

Cette contribution porte sur la compréhension brésilienne de l'idée de sauvegarde, observée au prisme de la politique patrimoniale liée à l'immatériel dans ce pays. Notre analyse diachronique de ce concept nous permettra de cerner plusieurs traits d'évolution du dispositif brésilien du patrimoine immatériel et du positionnement des acteurs sociaux vis-à-vis de celui-ci. Nous articulons ici une réflexion au sujet des jeux d'acteurs que la politique patrimoniale brésilienne appelle et à la manière dont les acteurs sociaux du patrimoine se saisissent des dispositifs de l'immatériel pour se constituer en acteurs légitimes de la vie publique et servir leurs revendications sociopolitiques. 
This article takes a look at the way the idea of heritage safeguarding is understood in Brasil, viewed from the point of view of intangible heritage policies in this country. Our diachronic analysis of the concept allows us to indentify several characteristics of the way the intangible heritage is managed in Brasil, and how social actors canrelate to these management procedures. We look in particular at the way different actors can use Brasilian heritage policies and how these actors can mobilise intangible heritage procedures in order to constitute themselves as legitimate partners in public life, and pursue their own socio-political aims.

\section{INDEX}

Mots-clés : sauvegarde, patrimonialisation, patrimoine immatériel, acteur social, développement humain

Keywords : safeguarding, heritage recognition, intangible hertiage, social stakeholders, human development

\section{AUTEURS}

\section{ELAINE BRITO}

Doctorante en sciences de l'information et de la communication, programme Culture, Patrimoine, Mémoire, Centre Norbert Elias, université d'Avignon et des Pays de Vaucluse (UAPV), France elainebritoca@gmail.com

\section{NOLWENN PIANEZZA}

Doctorante en sciences de l'information et de la communication, programme Culture, Patrimoine, Mémoire, Centre Norbert Elias, université d'Avignon et des Pays de Vaucluse (UAPV), France, chargée d'enseignement à l'université d'Avignon et des Pays de Vaucluse (UAPV) nolwenn.pianezza@gmail.com 